\title{
Handbook of Retinal OCT Eds: Jay S. Duker, Nadia K. Waheed, Darin R. Goldmann 2014, ISBN: 978-0-323-18884-5 Elsevier/Saunders
}

\author{
Bernd Kirchhof
}

Received: 16 June 2014 / Accepted: 21 June 2014 /Published online: 9 July 2014

(C) Springer-Verlag Berlin Heidelberg 2014

Structural intraretinal information is the key to progress in OCT examination. I, therefore, appreciate that this booklet focuses strictly on SD-OCT. A systematic approach to ophthalmology is provided wherever SD-OCT scanning is useful. The more information we gather, the more we need to understand the difference between clinically relevant and negligible data. It is amazing how many experienced clinicians use SDOCT routinely but cannot correlate the lines of a normal OCT to the underlying anatomical structure. More so, there is confusion about the many facets of disease and iatrogenic changes. Thus, OCT education is still to be improved and a handy handbook, like the one from Duker and colleagues, helps with simple things like where exactly to measure the size of a macular hole, where again the inner-outer segment line predictive in pucker surgery is, or if a tissue is of the nerve fibre layer or epiretinal membrane.

See, chloroquine maculopathy has made it into the textbooks, likewise subretinal perfluorocarbon bubbles!

This is, initially, not so much a book for looking up a specific case. The 177-page paperback size stimulates one to sit back and read it from the beginning to end. Even the experienced clinician will eventually find new information. To look up a specific question, there is an expert online databank linked to the purchase of the book, with databank query.

I fully recommend the booklet to anybody in residency and beyond facing, learning, and keeping up with advancements in technologies for examination of the eye.
B. Kirchhof $(\bowtie)$

Abt. für Netzhaut- und Glaskörperchirurgie, Zentrum für Augenheilkunde, Kerpenerstr. 62, 50937 Köln, Germany e-mail: bekirchhof@googlemail.com 